\title{
Bridging the Gap between Indian Urban Youth and Rural, Civic and Social Service Sector: A Collaborative Approach to Sustainable Development in Higher Education
}

\author{
Neeta Khurana \\ Department of Languages, Literature and Aesthetics, School of Liberal Studies \\ Pandit Deendayal Petroleum University \\ Raisan, Gandhinagar-382007 \\ Gujarat, India \\ Dr. Ritu Sharma \\ Head of Department, Psychology, School of Liberal Studies \\ Pandit Deendayal Petroleum University \\ Raisan, Gandhinagar-382 007 \\ Gujarat, India
}

\begin{abstract}
In the fast paced world of the urban set up, the youth in the cities is far removed from the concerns and realities of Rural India. The Internship Model proposed in the Higher Education segment which makes it mandatory for all technical students to undertake work with Non Government Organizations (NGO) helps bridge this gap. It provides an interface with society through social initiatives when young students align themselves with working with them thereby getting new and fresh perspectives and gain a deeper understanding of the environmental, social and economic issues from both an urban and rural perspective. Internship program is a pre-service training designed to render practical experience of a given job. For better execution of policies during one's professional career, a technocrat is required to come to terms with the realities of life. The internships are designed to impart to students values and/or duties which include justice, freedom, equality, diversity, authority, privacy, participation, truth, patriotism, human rights, rule of law, tolerance, mutual assistance, self-restraint and self-respect. The Objectives of Rural, Civic Social Service Internships are to develop a holistic view of social work and social welfare in the community, with special emphasis on the role of different agencies like Govt. departments and NGOs in human services; to allow students to apply, evaluate, test and integrate academic knowledge and theoretical concepts in a work setting; to reduce intellectual and geographical parochialism of the students; to understand the NGO and other civic bodies and welfare agency as an organization, and understand its structure, functions, activities and sources of funding; to develop an understanding of the opportunities in working with diverse populations.

The present paper is based on a study conducted on a group of 687 engineering students of First Year of Gujarat (Ahmedabad). Feedback from the students about the Internships and feedback of the coordinators from over $187 \mathrm{NGO}$ 's, Government and Civic and Social Service organizations was taken to understand the reach out of the Urban Youth and the impact it had on their understanding of the people of rural India and the functioning of the NGO's, Government and Civic bodies. The role of Higher Education to bridge the Gap is also discussed and analyzed. Findings of the survey and internship feedback reflected a high acceptance and a strong sense of sensitivity towards rural population and the amount of work that goes into making efforts to create a change for the betterment of less privileged people. The role of Higher Education in bridging this gap between Urban Youth and Rural population becomes significant as the future workforce is sensitized to the real India which dwells on the periphery of the Urban modern glitz of the smart cities hence leading to an assurance
\end{abstract}


that this will lead to inclusivity and acceptance of people from all across the spectrum of Indian populace.

KEYWORDS: Sustainability; Higher Education; Urban Youth; Bridging Gap; Employability Skills; Rural.

\section{INTRODUCTION}

Historically speaking, work and learning have always been separated. According to this difference, learning was an ordeal which ended in work. In the recent decades though, the distance between work and learning has bridged significantly. Vocational training has been in vogue for long now. The emphasis on education only in the type of trade a person wants to pursue forgoing traditional academics is the principle driving vocational education. As more and more educational institutions adopt this method, the trial period for internships and training-cum-learning modules is now over so to speak. It would be right to claim that internship programs are the only site of innovation and experiential learning that modern courses offer. Value imparted by these internships is mostly considered experiential and therefore not verifiable. Recent trend in top universities suggests that Internships are now looked at as being beneficial not just for employers, but also for academia. Therefore, this seems to be a great time to invest in not just in the idea of internships, but also in mapping its benefits.

Three clear trends are perceptible in this field:

1. The historical separation between work and learning is clearly being bridged.

2. In order to find well-honed talent, businesses and NGO's are communicating at a deeper level with universities and not just their future employees.

3. Internship is no more limited to being a training program. It is a part of essential learning with due weightage in credits. This is happening even as institutions realise the limits of a curriculum based program world over.

\section{Need for Programs like the RI-CSSI}

The growing need for RI-CSSI and similar programs has spawned academic interest in it. We would like to suggest that Internship related to Management/Finance/Commerce are almost always precursor to employment. It is to be stressed that the program run by Pandit Deendayal Petroleum University is a well-directed attempt at going beyond the employment needs of student community. It was thus a categorical imperative to use a Kantian term that Civic and Social Responsibility was made part of the official nomenclature of the program.

This is not a study of phenomenon. It is verily a study of ascertainment to put it simply. This project began as a record-keeping of datum to manage an operation so large. But the experiences and feedback of students and NGO's motivated us to perceive this data in an academic light with cogent classification.

\section{Role of NGO's in Education}

As mentioned earlier, the civic and social responsibility aspect of the internship of our module has a lot going in its favour because of the wide participation of a large network of NGO's. This form of internships challenge the predominant knowledge-economy perspective that places a lot of 


\section{Sustainability or sustainable development? Clearing the smog:}

Though for our purposes in this empirical study, academic egotism of definitions hardly matters, the chasm between the two shall have to be cleared. Sustainability is seen as a paradigm for thinking about the future in which environmental, societal, and economic considerations are balanced in the pursuit of an improved quality of life. The ideals and principles behind it lays on broad concepts such as intergenerational equity, gender equity, social tolerance, poverty alleviation, environmental preservation and restoration, natural resource conservation, and building just and peaceful societies.[Encyclopaedia of Corporate social responsibility]

Sustainable development on the other hand defined by the United Nations Brudtland commission development that meets the needs of the present without compromising the ability of future generations to meet their own needs." This implies that we need to look after our planet, our resources and our people to ensure that we can live in a sustainable manner and that we can hand down our planet to our children and our grandchildren to live in true sustainability. [1]

Sustainable development is built around six axes:

1. Reviving growth

2. Changing the quality of growth

3. Meeting essential need for jobs, energy, water and sanitation

4. Conserving and enhancing the resource base

5. Reorienting technology and managing risk, and

6. Merging environment and economies in decision-making

The main thrust of sustainable development therefore is that global environment protection and economic growth should proceed hand in hand.

\section{The need for Civic and Social Responsibility}

Management guru Peter Drucker argued in the 1990's that we are in the midst of a massive shift of power when the current owners of capital will be replaced by knowledge makers. Not only would knowledge assume power, but with it would come greater rewards and creativity. Two decades on, we are living in a world full of discontinuities, paradoxes and inequalities. Far from creating additional rewards, this system has led to a situation where highly skilled labour is in demand, but work is offered to those who are willing to work at the lowest wage.

Bursts of creativity are followed by routinisation to enable companies to make profits. For instance, Steve Jobs was lauded as a genius for giving us iPads, but Chinese companies were mauled for producing similarly efficient devices at half the price. This is a problem of economyeducation relationship. [Ibid, Routledge Handbook] There are various ways to think about this relationship, but one of the key manners is to establish difference between skill and knowledge. Companies hiring mass jobs are often looking for candidates who can replicate a process in the most efficient and fast manners. Educational institutions over the years have aimed at producing such "highly skilled graduates" undermining the promise of creativity that such education initially offered. But since access to education is not universal and equitable, education itself becomes the site of struggle. The struggle is around access, entry and participation in a race to get ahead. This system then creates more inequalities by trying to limit the access to such systems based on merit. Thus the hope that education will bring social revolution is lost for all cause. 


\section{Sustainability and Higher Education: Reform and Innovation}

The onus of retrieving a sustainable society thus is placed not on those who run education, but those who make knowledge. A consistent complain about the academic fraternity has been that those who are vocal about social equity and welfare rarely venture outside the book to defend. This criticism in recent years, has spawned the dawn of internship with a conscience to help and not just train. This has succeeded more in third world countries like India more because routinisation has not taken over the education-economy relationship as much as it has in the West.

The reform our education system has seen in recent times has been immense. While the transformation has been witnessed across the board in higher education that include curricular, assessment, learning tools, participation of stakeholders etc, the clincher has been the mandatory participation of students in socially accountable work carrying academic credits. Innovation and reform both call for an impetus to change, but there are key differences between the two. While Reform is described as a "top-down" approach; either system-wide or anchored within several different institutions; based on external processes; Innovation is characterized as a "bottom-up" or "grassroots" approach; based on internal processes. ${ }^{1}$

\section{Agenda 21 and achieving sustainable development through higher education}

Agenda 21 is the most comprehensive document outlining role of higher education in promoting and enhancing a sustainable environment. There is still a considerable lack of awareness of the interrelated nature of all human activities and the environment, due to inaccurate or insufficient information. Developing countries in particular lack relevant technologies and expertise. There is a need to increase public sensitivity to environment and development problems and involvement in their solutions and foster a sense of personal environmental responsibility and greater motivation and commitment towards sustainable development.

The objective is to promote broad public awareness as an essential part of a global education effort to strengthen attitudes, values and actions which are compatible with sustainable development. It is important to stress the principle of devolving authority, accountability and resources to the most appropriate level with preference given to local responsibility and control over awareness-building activities. Countries with the support of the United Nations system should identify workforce training needs and assess measures to be taken to meet those needs. A review of progress in this area could be undertaken by the United Nations system in $1995 .^{2}$

\section{The National Education Policy and Internship method of assessing social responsibility}

Ensure that school and higher education as well as adult education programmes inculcate an awareness among children, youth and adults of India's rich heritage, glorious past, great traditions and heterogeneous culture, and promote acquisition by the learners at all levels of

${ }^{1}$ Reform and Innovation in Higher Education A Literature Review Prepared by the National Center for Postsecondary Improvement: Project 5.3. http://ncpi.stanford.edu\}

${ }^{2}$ http://www.unep.org/documents.multilingual/default.asp?DocumentID=52\&ArticleID=4415 \&l=en 
values that promote responsible citizenship, peace, tolerance, secularism, national integration, social cohesion and mutual respect for all religions, as well as universal values that help develop global citizenship and sustainable development ${ }^{3}$.

\section{Two Approaches to Sustainable Development}

Figure 1

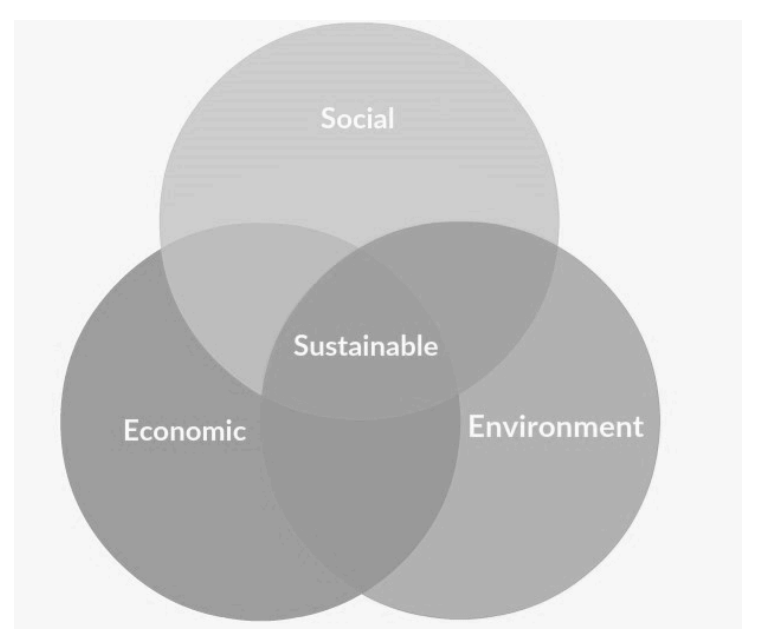

APPROACH A

As is evident from the above figure, this approach finds sustainability at the interjection of the economic, social, and environmental efforts of a community. Further, there are productive collaborations between each of the three. This gives us a three prong formulaic relation that effects and offers sustainability. These are as follows:

1. Economic+Social= Equitable Growth

2. Social+Environment=Volunteering/Activism/Lobbyism

3. Environment+Economic $=$ Free market environmentalism

1. While the question of difference between growth and development is an important one, we must hasten to clear that equitable growth is achievable only when business interests are allied with societal aspirations. The aim of sustainability in this dyad is distributive justice. Ex: Rights movement of geographically disadvantaged groups.

2. Devoid of profit motive, when a community engages in civil and socially responsible action, it serves as a precursor to legislative action aimed at sustainable development. Business is kept aside from this dyad and the state is an agency of the people. The aim of sustainability in this dyad is democracy. Ex: Civil society movements like Greenpeace.

3. A third very interesting phenomenon has taken shape in recent years. It would be unfair to say that society is absent from the scheme in which economic means are found to sustain the environment, but in the final analysis it is present only stealthily. This is because the price of sustainability or costs of unsustainable development is decided by ecomics and society. The aim of sustainability in this dyad is to earn legitimate profits from the environmental crises. Ex: A corporate house selling women's underwear called the "greenest Panties in the world" on the 
pretext that buying them will change the lives of cotton growers in India for good. Most of "organic" industry can be covered in this dyad. ${ }^{4}$

Figure 2

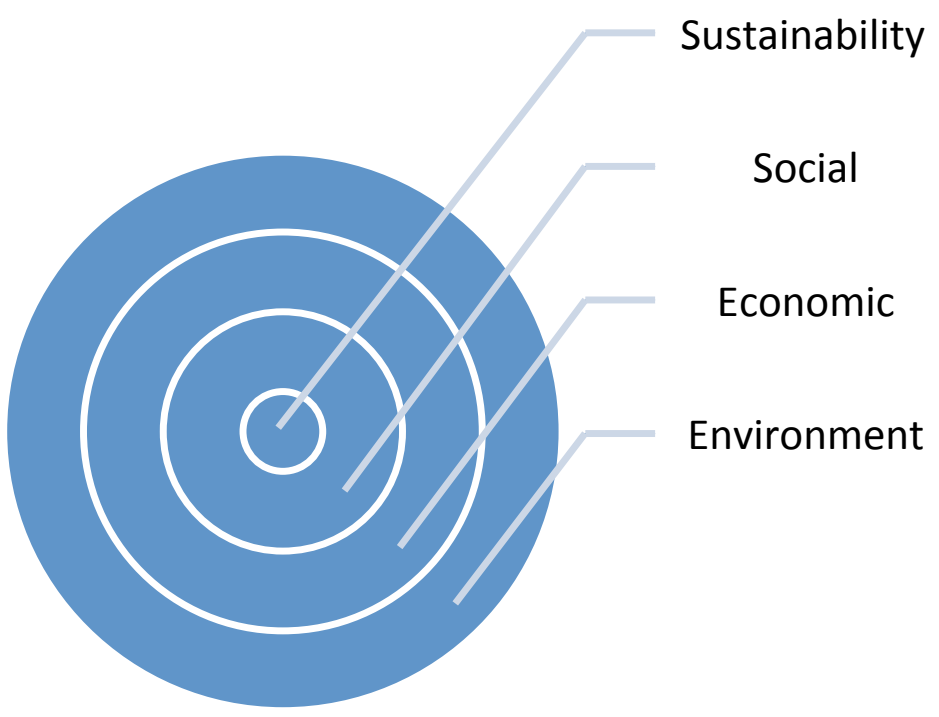

APPROACH B

In Approach B as highlighted the social economic and environmental spheres are not seen as a conjugal triad. Rather they are seen as ascriptively related to sustainability and have their own unattuned relation at the same time. Sustainability acquires the central position here and there are no formations of dyads. The social is seen as the most powerful and proximate sphere of sustainability because this approach assumes that it is the society that is the guardian of economy and environment.

\section{The following assumptions are made to better explain this approach of sustainability:}

1. Environment needs attention of society to replenish and correct the damages caused to it.

2. Left to economic interest alone, sustainable development cannot be achieved.

3. Society is most likely to wake up to the needs of a sustainable environment because society in the final analysis is the guardian of environment.

4. The uncertain and questionable role of State and Market in preserving environment is taken care of by the society's impetus on education directed at a sustainable life.

Hence this approach places great value on the system of higher education in bringing a responsible citizenry together for a concerted effort in achieving sustainable environment and development. The foremost step in this process is a forbearing system of sensitivity and accountability. The second perspective therefore squarely puts the urgent and timely onus of "sustaining" on the society.

\section{FINDINGS AND DISCUSSION}

The Analysis intended to capture the views of respondents on following parameters:

${ }^{4} \underline{\text { http://www.fairobserver.com/region/central_south_asia/the-greenest-panties-in-the-world-90091/ }}$ 
1. Number of NGO representation across various states in India During the year 2015 for 687 engineering students.

2. Comprehensive NGO feedback on a five point scale on factors like Ability and Initiative to learn, reading,writing and communications skill, Creative thinking and problem solving skills, Interpersonal and team work, basic work habits, character attributes ,sincerity, punctuality, time management, contribution towards the project and overall performance of the intern.

3. Percentage of Student's Internship Exposure across Various NGO Categories like welfare of Health welfare, social, ecological, educational, tribal, women and specially abled. Also Industrial and organisational and research and development welfare was mapped.

The findings evidently reveal the significance of NGO based social integration experiential learning model in skill development of engineering students. Holistic and application driven nature of Internship programs like the RICSSI clearly indicate significance of such program in training technical workforce for preparedness of future workplace.

Table No. 1

Number of NGO representation across various states in India during year 2015

\begin{tabular}{|c|c|}
\hline STATE & NO. OF NGOs \\
\hline Assam & 2 \\
\hline Bihar & 1 \\
\hline Gujarat & 151 \\
\hline Haryana & 1 \\
\hline Himachal Pradesh & 1 \\
\hline Karnataka & 1 \\
\hline Kerela & 2 \\
\hline Madhya Pradesh & 3 \\
\hline Maharashtra & 2 \\
\hline Mizoram & 1 \\
\hline New Delhi & 2 \\
\hline Orissa & 1 \\
\hline Rajasthan & 15 \\
\hline Uttar Pradesh & 5 \\
\hline Total & 188 \\
\hline
\end{tabular}


Table no. 2

\begin{tabular}{|l|l|l|l|l|l|l|l|l|l|l|l|}
\hline \multicolumn{10}{|c|}{ NGO Feedback } \\
\hline & $\begin{array}{l}\text { Ability } \\
\text { and } \\
\text { initiativ } \\
\text { e to } \\
\text { learn }\end{array}$ & $\begin{array}{l}\text { Reading/ } \\
\text { Writing/ } \\
\text { Commu- } \\
\text { nication } \\
\text { Skills }\end{array}$ & $\begin{array}{l}\text { Listening \& } \\
\text { oral } \\
\text { Communic } \\
\text { ation Skills }\end{array}$ & $\begin{array}{l}\text { Creative } \\
\text { Thinking } \\
\text { and } \\
\text { Problem } \\
\text { Solving } \\
\text { Skills }\end{array}$ & $\begin{array}{l}\text { Interp } \\
\text { erson } \\
\text { al and } \\
\text { team } \\
\text { work }\end{array}$ & $\begin{array}{l}\text { Basic } \\
\text { Work } \\
\text { Habits }\end{array}$ & $\begin{array}{l}\text { Char } \\
\text { acter } \\
\text { Attri- } \\
\text { butes }\end{array}$ & $\begin{array}{l}\text { Sincerity } \\
\text { Attribute } \\
\text { s }\end{array}$ & $\begin{array}{l}\text { Punctu } \\
\text { ality \& } \\
\text { Time } \\
\text { Mgt }\end{array}$ & $\begin{array}{l}\text { Contri } \\
\text { bution } \\
\text { towar } \\
\text { ds the } \\
\text { projec } \\
\text { t }\end{array}$ & $\begin{array}{l}\text { Overall } \\
\text { performan } \\
\text { ce } \\
\text { intern } \\
\text { the }\end{array}$ \\
\hline Excellent & 47.7 & 36.1 & 39.4 & 31.9 & 39.8 & 26.7 & 40.7 & 47.1 & 37.4 & 37.8 & 39.2 \\
\hline Good & 43.8 & 50.1 & 47.7 & 7.0 & 49.4 & 59.9 & 48.4 & 46.4 & 47.3 & 48.8 & 50.1 \\
\hline Average & 7.7 & 12.5 & 10.5 & 14.2 & 9.9 & 12.9 & 10.5 & 5.9 & 13.6 & 13.1 & 7.6 \\
\hline Poor & 0.0 & 1.1 & 2.0 & 52.5 & 0.4 & 0.0 & 0.2 & 0.4 & 1.5 & 0.2 & 0.0 \\
\hline Very Poor & 0.0 & 0.0 & 0.0 & 0.7 & 0.0 & 0.4 & 0.0 & 0.0 & 0.0 & 0.0 & 0.0 \\
\hline
\end{tabular}

Table No. 3

Percentage of Student's Internship Exposure across Various NGO Categories

\begin{tabular}{|l|c|c|c|}
\hline \multicolumn{1}{|c|}{ Category } & No. of NGOs & $\begin{array}{c}\text { No. of } \\
\text { Students }\end{array}$ & $\begin{array}{c}\text { Percentage of Students } \\
\text { in different categories } \\
\text { (\%) }\end{array}$ \\
\hline Health Welfare & 43 & 147 & 25.7 \\
\hline Social Welfare & 39 & 152 & 26.6 \\
\hline Ecological Welfare & 17 & 43 & 7.5 \\
\hline Welfare of the underprivileged & 26 & 62 & 10.9 \\
\hline Educational Welfare & 22 & 52 & 9.1 \\
\hline Tribal Welfare & 12 & 44 & 7.7 \\
\hline Welfare of specially abled & 10 & 33 & 5.8 \\
\hline Industrial and Organisational & 1 & 1 & 0.2 \\
Welfare & 17 & 34 & 6.0 \\
\hline Women Welfare & 1 & 3 & 0.5 \\
\hline Research and Development & 188 & 571 & \\
\hline TOTAL & & & \\
\hline
\end{tabular}

\section{RI-CSSI AND SDG'S}

The Sustainable Development Goals (SDGs), officially known as transforming our world: the 2030 Agenda for Sustainable Development are an intergovernmental set of aspiration Goals with 169 targets. Spearheaded by the United Nations, The Goals are contained in paragraph 54 United Nations Resolution A/RES/70/1 of 25 September $2015^{5}$

The RI-CSSI lends into at least five of the SDG's. What follows is a textual analysis.

- 1. a under "No Poverty" talks about "enhanced development co-operation". This is possible only from a civic and socially responsible citizenry that is capable of bolstering the global movement against poverty alleviation. Governments will have to spend less on awareness programs if schools made RICSSI necessary.

${ }^{5}$ http://www.un.org/ga/search/view_doc.asp?symbol=A/RES/70/1\&Lang=E (last accessed on 12 August, 2016) 
- 4.7 under "Quality Education" expects us to "ensure that all learners acquire the knowledge and skills needed to promote sustainable development". Also, putting the sensitivity of students on the edge is crucial if we have to "preserve culture's contribution to sustainable development"

- 12.8 under "Responsible consumption and production" gives the mandate of providing "relevant information and awareness for sustainable development and lifestyles in harmony with nature". Maintaining harmony with nature will need breeding young and local leaders who have deliverable solutions for communities.

- 13.3 under "Climate Action" is focussed at "improving education and awareness raising". The RICSSI office has data demonstrating that students developed drive to work for change from immediately preceding their placements. The syllabus based study postpones such experiences of empowerment till after work.

- 17.16 and 17.17 under "Partnership for the Goals" it is to be learnt that the "multi stakeholder partnerships that mobilise and share knowledge, expertise have often failed to foster significant and durable changes due to shackles of culture and local differences. Now a universal based on coherent training modules that aim at sensitising tomorrow's leaders promises to change it. Programs like RICSSI also promote and encourage effective public-private partnerships.

\section{CONCLUSION}

Firstly, Internship programs like the RICSSI are splintering the dyad between work and study. Secondly, the role of NGO's in improving student-confidence sensitivity and awareness to a sustainable living has been sufficient enough to promulgate our next sessions with greater roles for them. Thirdly, a healthy number of students showed initiative and leadership qualities in answering their duties as interns. Fourthly, managing an Internship involving such a large number of students required the know-how from various departments that led to collaboration otherwise not possible.

\section{References}

National Draft Education Policy, 2016

R. Govindam Madhumita Bandhopadhyay Access to Elementary Education in India, country analytical review by Consortium for Research on Educational Access Transitions and Equity(CREATE),. University of Sussex United Kingdom. July 2008

Dave Hill, (eds) The Rich World and the Impoverishment of Education, diminishing Democracy Equity and Worker's Rights, Routledge, New York, 2009..Draft Document of the National Education Policy of India

Robert L. Geiger, Research Universities and the Paradox of Market Place, Stanford University Press. California, 2004 